\title{
Improving the efficiency of the heat and power system, due to the synthesis of control based on the synergistic concept
}

\author{
Viktor P. Lapshin ${ }^{1}$, Veronika V. Hristoforova ${ }^{1}$, Alexey A. Zakaluyzhnyy ${ }^{1, *}$, \\ Anna R. Klueva ${ }^{1}$, and Pham Dinh Tung ${ }^{2}$ \\ ${ }^{1}$ Don State Technical University, 344000 Rostov-on-Don Gagarin square 1, Russia \\ ${ }^{2}$ Department “Aerospace technology and equipment”, Le Quy Don Technical University, Hanoi, \\ Vietnam
}

\begin{abstract}
The article describes a special case of the synthesis of the electromechanical system for controlling the thermal regime by the method of analytical design of aggregated regulators. The task was to base the synthesis of the optimal in speed electromechanical system for stabilizing the operating modes of the thermodynamic system, based on the use of the Peltier module as a thermal converter.
\end{abstract}

\section{Statement of the research problem}

At the end of the 20th century, a new approach to the synthesis of control systems emerged, which from its author A. Kolesnikov. called the method of Analytical Design of Aggregated Regulators (AKAR) [1-10]. The basis of this approach is the concept of synthesis of nonlinear feedbacks ensuring the asymptotic stability of the control system with respect to the required (from a practical point of view) motion (attractor) in the state space of the system [1]. The difference of this method from the methods of synthesis of optimal control systems is what is missing here as a criterion for optimizing the control system [11]. From the point of view of the implementation of the synthesis procedure, the AKAR method has an undoubted advantage over the synthesis methods of optimal systems, expressed in the absence of restrictions on the nonlinearity of the initial system of differential equations.

From a practical point of view, the synthesis of control processes occurring in the control systems of thermal modes of microprocessor systems, is of great interest. The very method of AKAR allows to get control extreme in terms of energy costs [1-2]. Thus, the synthesis of control based on the disclosure of a synergistic concept will improve the energy efficiency of the thermodynamic system considered in the work.

\footnotetext{
* Corresponding author: zakalizhnuy-95@yandex.ru
} 


\section{Synthesis of a mathematical model}

The basis of the electromechanical control system under consideration is the 7015-C electric motor, which provides for the conversion of electrical energy into mechanical energy of motion of the system actuators. The mathematical model of a DC motor with collector control is described by the following system of equations [12]:

$$
\begin{aligned}
& U-c_{e} \omega=L \frac{d i}{d t}+R i \\
& c_{m} i=J \frac{d \omega}{d t}+M_{c}
\end{aligned}
$$

where $\mathrm{U}$ - the voltage applied to the engine manifold;

$\mathrm{i}$ - the current consumed by the motor;

$\mathrm{R}, \mathrm{L}$ - motor electrical parameters;

$J$ - the parameter characterizing the inertial properties of the motor armature is the reduced inertia moment of all rotating masses;

$\omega$ - engine armature speed;

$M_{c}=\mu \omega^{2}$ - external applied moment of resistance, $\mu=1,1 \cdot 10^{-7}$;

$c_{m}, c_{e}$ - mechanical and electric permanent motor;

Based on the passport data of the electric motor, we will perform calculations of unknown quantities in the system of equations (1).

Knowing the supply voltage of the engine and the speed of rotation of the engine, we find the mechanical and electrical components of the engine:

$$
\begin{gathered}
U=c_{e} \omega \rightarrow c_{e}=\frac{U}{\omega} \\
c_{e}=\frac{12}{125,6}=0,1
\end{gathered}
$$

The mechanical component $\mathrm{c}_{\mathrm{m}}$ of the engine in the calculations is chosen approximately equal to the electric component. Considering that the electromagnetic moment of the engine must be greater than the moment of resistance, we take the value of the mechanical component equal to 0.078 .

The anchor circuit resistance and inductance were obtained experimentally and are equal, respectively, $79.6 \mathrm{ohms}$ and $0.0048 \mathrm{H}$.

As it is known from sources, the dynamics of thermal processes is of a pronounced aperiodic nature, in connection with this, the thermodynamic parameters of the model under consideration are described by the following differential equation:

$$
T \frac{d \theta}{d t}+\theta=N_{1}-N_{2}
$$

where $\theta$ - current temperature;

$\mathrm{N}_{1}$ - source power (the quantity that shows how much heat the hot side of the Peltier element receives during operation), is constant;

$\mathrm{N}_{2}$ - power flow (the value showing how much heat the fan removes from the Peltier element per unit time), is some function of angular speed: $N_{2}=f(\omega)$;

$\mathrm{T}$ - Peltier time constant. Empirically derived - 2,85 c.

The coefficient characterizing the quantitative conversion of electric energy $\mathrm{E}_{0}$, was obtained experimentally and is equal to 0.188 . 
Knowing the useful power of the Peltier element and the coefficient $E_{0}$, we find the value

$$
N_{1}=\frac{P_{p}}{E_{0}} \text { or } N_{1}=\frac{42}{0,188} \approx 223,58(\text { Дж) }
$$

Assuming that the power of the drain depends on the speed of rotation of the fan and the heat outflow will be aperiodically associated with the power of the source, suppose $f(\omega)=N_{1}\left(1-e^{-\alpha \omega}\right)$. Then $N_{2}=N_{1}\left(1-e^{-\alpha \omega}\right)$. Based on this, we rewrite the differential equation (3) as follows:

$$
\begin{gathered}
T \frac{d \theta}{d t}+\theta=N_{1}-N_{2} \rightarrow \frac{d \theta}{d t}=\frac{1}{T}\left(N_{1}-N_{2}\right)-\frac{\theta}{T} \rightarrow \frac{d \theta}{d t}=\frac{1}{T}\left(N_{1}-N_{1}\left(1-e^{-\alpha \omega}\right)\right)-\frac{\theta}{T} \\
\frac{d \theta}{d t}=\frac{N_{1}}{T}\left(1-1+e^{-\alpha \omega}\right)-\frac{\theta}{T} \\
\frac{d \theta}{d t}=\frac{N_{1}}{T} e^{-\alpha \omega}-\frac{\theta}{T}
\end{gathered}
$$

For ease of modeling, we denote the variables $\theta=x_{1}, \omega=x_{2}, i=x_{3}$, and as constant we introduce $a_{11}=\frac{1}{T}=\frac{1}{2,85}=0,35, a_{12}=\frac{N_{1}}{T}=\frac{223,58}{2,85}=78,45, a_{22}=\frac{\mu}{J}=\frac{1,1 \cdot 10^{-7}}{1,423 \cdot 10^{-5}}=0,0079$, $a_{23}=\frac{c_{m}}{J}=\frac{0,078}{1,423 \cdot 10^{-5}}=5487, \quad a_{32}=\frac{c_{e}}{L}=\frac{0,1}{0,0048}=20,83, \quad a_{33}=\frac{R}{L}=16583,3$, $b=\frac{1}{L}=\frac{1}{0,0048}=206,74$, then system (5) takes the following form:

$$
\begin{aligned}
& \frac{d x_{1}}{d t}=-a_{11} x_{1}+a_{12} e^{-\alpha x_{2}} \\
& \frac{d x_{2}}{d t}=-a_{22} x_{2}^{2}+a_{23} x_{3} \\
& \frac{d x_{3}}{d t}=-a_{32} x_{2}-a_{33} x_{3}+b U
\end{aligned}
$$

The system of equations (6) is the desired mathematical model of the system.

\section{Control synthesis based on the AKAR method}

For the synthesis of the control system by the AKAR method, it is possible not to make a transition to the abstract phase case of the state space, but it is convenient to use the original system (1), but it is necessary to convert it to the following form: 


$$
\begin{aligned}
& \frac{d x_{1}}{d t}=-a_{11} x_{1}+a_{12} e^{-\alpha x_{2}} \\
& \frac{d x_{2}}{d t}=-a_{22} x_{2}^{2}+a_{23} x_{3} \\
& \frac{d x_{3}}{d t}=-a_{32} x_{2}-a_{33} x_{3}+b U
\end{aligned}
$$

The variable characterizing the temperature of the heating side of the Peltier element $\left(\mathrm{x}_{1}\right)$ is the output coordinate of the system; therefore, to form requirements for the desired system behavior in the state space, we introduce the following macro variable of the order $\psi_{1}=\mathrm{x}_{1}--\mathrm{x}_{01} \rightarrow 0$, where $\mathrm{x}_{01}$ - preset, required coordinate value $\mathrm{x}_{1}$. The value of the rate of temperature change should ensure the temperature of the heating side of the Peltier element to the value specified above, for this we introduce another macro variable $\psi_{2}=\mathrm{x}_{2}-\varphi_{1}\left(\mathrm{x}_{1}\right) \rightarrow 0$, where $\varphi_{1}\left(\mathrm{x}_{1}\right)$ some function describing aspiration $\mathrm{x}_{2} \rightarrow \varphi_{1}\left(\mathrm{x}_{1}\right)$ in steady state.

Next, enter the macro variable order by coordinate $\psi_{3}=x_{3}-\varphi_{2}\left(x_{1}, x_{2}\right) \rightarrow 0$, where $\varphi_{2}\left(x_{1}, x_{2}\right)$ some function that describes the relationship between the coordinates in the stationary state of the system and, therefore, $\mathrm{x}_{3} \rightarrow \varphi_{2}\left(\mathrm{x}_{1}, \mathrm{x}_{2}\right)$.

For newly introduced macro variables $\psi_{1}, \psi_{2}, \psi_{3}$, we require the asymptotically stable law of change, that is, the implementation of the following system of differential equations:

$$
\left\{\begin{array}{l}
T_{1} \frac{d \Psi_{1}}{d t}+\Psi_{1}=0 \\
T_{2} \frac{d \Psi_{2}}{d t}+\Psi_{2}=0 \\
T_{3} \frac{d \Psi_{3}}{d t}+\Psi_{3}=0
\end{array}\right.
$$

where $T_{1}, T_{2}, T_{3}$ - time constants determine the rate of aspiration of the introduced macro variables to zero, or, in other words, the speed of an arbitrary trajectory of the system in the state space to the attractor required from a technological point of view. The system of equations introduced in expression (13) expanded the state space of the system from the $3 \mathrm{rd}$ to the 6th, which is one of the main provisions of the AKAR method, further synthesis of the control system is reduced to a step-by-step process of decomposition (compression) of this space to the initial level.

As a result of the decomposition of the state space of the control system, we define the value of the control in the coordinates of the controlled process; the method's operation is considered in more detail in our papers [4]:

$$
\begin{aligned}
T_{3} b U & =T_{3} a_{32} x_{2}+T_{3} a_{33} x_{3}+T_{3} \frac{d \varphi_{2}\left(x_{1}, x_{2}\right)}{d t}-x_{3}+\varphi_{2}\left(x_{1}, x_{2}\right) \\
U & =\frac{1}{b}\left(a_{32} x_{2}+a_{33} x_{3}+\frac{d \varphi_{2}\left(x_{1}, x_{2}\right)}{d t}+\frac{\varphi_{2}\left(x_{1}, x_{2}\right)-x_{3}}{T_{3}}\right)
\end{aligned}
$$

Expression (9) determines the asymptotically stable control action on the control system described by equations (7).

After all the above manipulations, the system (8) will take the following form: 


$$
\begin{aligned}
\frac{d x_{1}}{d t} & =-a_{11} x_{1}+a_{12} e^{-\alpha x_{2}} \\
\frac{d x_{2}}{d t} & =-a_{22} x_{2}^{2}+a_{23} x_{3} \\
\frac{d x_{3}}{d t} & =\frac{d \varphi_{2}\left(x_{1}, x_{2}\right)}{d t}+\frac{\varphi_{2}\left(x_{1}, x_{2}\right)-x_{3}}{T_{3}}
\end{aligned}
$$

However, the most interesting is the dynamics of the control system synthesized by us. As a rule, to evaluate the resulting system from the point of view of dynamic properties, Matlab models are used in the environment [14-19]. We will also use this modeling environment and explore the synthesized system. When modeling system (10), the results presented in Figure 1 were obtained:
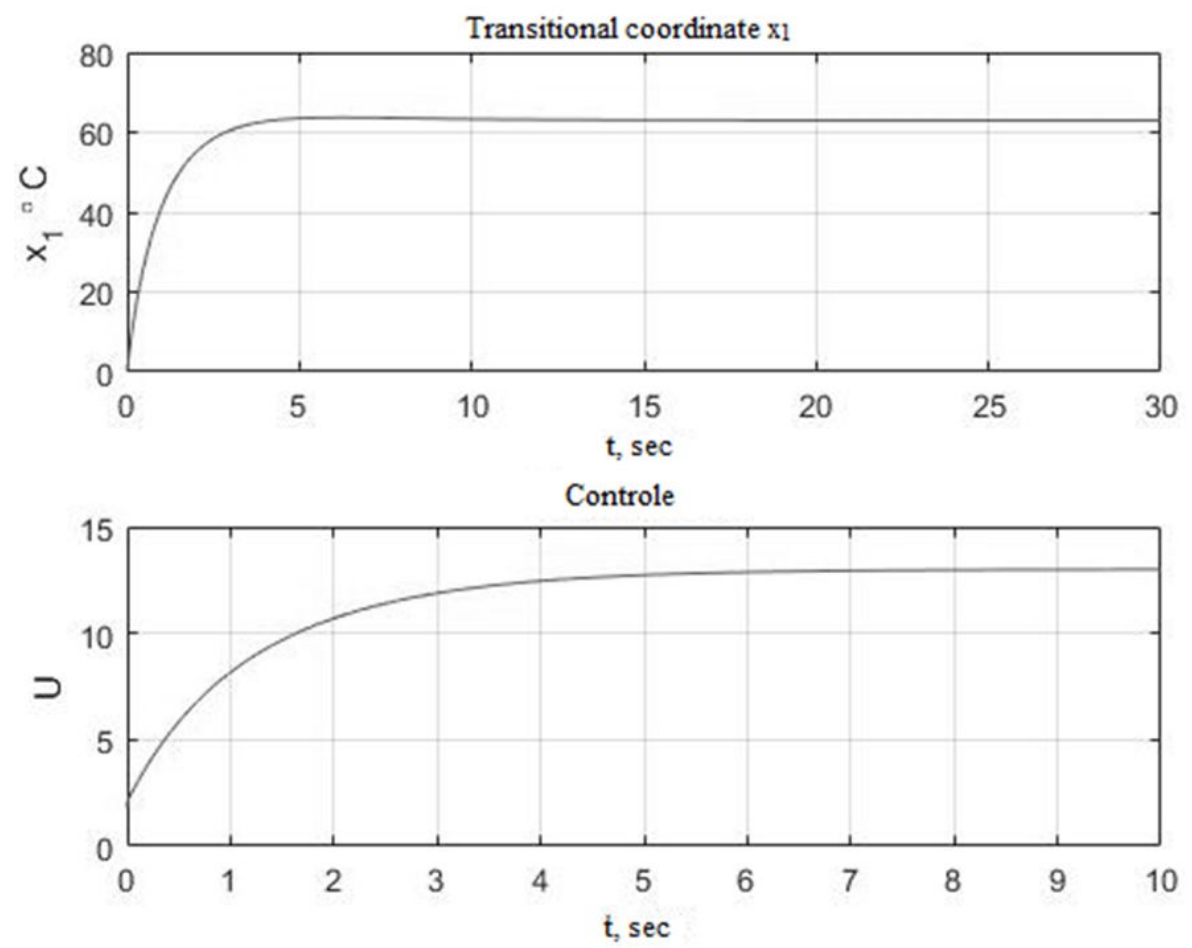

Fig.1. Transitional coordinate $\mathrm{x}_{1}$ and control schedule.

From figure 1 it can be seen that the time of the transition process along the $\mathrm{x}_{1}$ coordinate with the values of the parameters $T_{1}=2.88, T_{2}=0.01, T_{3}=0.0099$ is about 5 seconds. This is one of the best in terms of energy efficiency of many simulation results, unfortunately the volume of the article does not allow to bring everything.

\section{Conclusion}


Thus, the results presented in this paper allow us to speak about the possibility of applying the synergistic concept of synthesis in the development and creation of energy-efficient thermodynamic systems.

\section{References}

1. A. A. Kolesnikov, Prikladnaya sinergetika: osnovy sistemnogo sinteza (TTI YUFU, Taganrog, 2007)

2. A. A. Kolesnikov, Sinergetika i problemy teorii upravleniya (Fizmatlit, Moscow, 2004)

3. V.L. Zakovorotny and others, Sinergeticheskij sistemnyj sintez upravlyaemoj dinamiki metallorezhushchih stankov s uchetom evolyucii svyazej (DGTU, Rostov on/D, 2008)

4. M. P. Lazarević, International Journal of Non-Linear Mechanics, 73, 31 (2015)

5. A. A. Kuz'menko, 5th International Congress on Ultra Modern Telecommunications and Control Systems and Workshops (ICUMT), IEEE, 146 (2013)

6. I. Kondratiev, A. Nikiforov, G. Veselov, A. Kolesnikov, IEEE International Electric Vehicle Conference, IEEE, 1 (2012)

7. I. Kondratiev, R. Dougal, G. Veselov, A. Kolesnikov, IEEE Control Applications, (CCA) \& Intelligent Control, (ISIC), 495 (2009)

8. A. Bezuglov, A. Kolesnikov, I. Kondratiev, J. Vargas, Proc. of the 9th World MultiConference on Systemics, Cybernetics and Informatics, 121 (2005)

9. V. P. Lapshin, I. A. Turkin, A. A. Zakalyuzhnyy, V. F. Khlystunov, G. A. Kuzin, MATEC Web of Conferences, 226, 02012 (2018)

10. V. P. Lapshin, Turkin I. A., V. V. Khristoforova, 2018 International Russian Automation Conference (RusAutoCon), IEEE, 1 (2018)

11. L. S. Pontryagin, Matematicheskaya teoriya optimal'nyh processov (Nauka, Moscow, 1976)

12. V.P. Lapshin, I.A. Turkin, Avtomobil'naya promyshlennost', 1, 16 (2017)

13. V.P. Lapshin, I.A. Turkin, Russian Engineering Research, 35, 10, 795 (2015)

14. V.P. Lapshin, I.A. Turkin, Procedia Engineering, 206, 594 (2017)

15. V.L. Zakovorotny, V.P. Lapshin, T.S. Babenko, Procedia Engineering, 206, 68 (2017)

16. S. V. Nosachev, M. V. Chuveiko, M.Yu. Zhukova, G. A. Kuzin, I. A. Khozyaev, MATEC Web of Conferences, 226, 02006 (2018)

17. S. V. Nosachev, M. V. Chuveyko, MATEC Web of Conferences, 132, 02004 (2017)

18. V.S. Bykador, Lecture Notes in Mechanical Engineering, Springer Nature Switzerland AG, 293 (2019)

19. V.S. Bykador, Zh.E. Bykador (Bronzova), Procedia Engineering, 206, 151 (2017) 